\title{
Pengaruh Perbedaan Suhu Pemeliharaan terhadap Histopatologi Insang dan Kulit Ikan Komet (Carassius auratus)
}

\section{The Effects of Different Cultivation Temperature Against Histopathology of Gill and Skin on Carp (Carassius auratus)}

\section{Asep Sumantri, Mulyana and Fia Sri Mumpuni}

\begin{abstract}
The research is aimed to know the effects of different temperature against of histopathology of gill and skin on carp (Carassius auratus). The research used 30 samples of carp that is divided into 3 treatments. The treatments are different cultication temperature, these were $25.0{ }^{\circ} \mathrm{C}, 28.5{ }^{\circ} \mathrm{C}$ and $32.0^{\circ} \mathrm{C}$. The research showed histopathology on gill and skin of carp at treatment of $32{ }^{\circ} \mathrm{C}$. Skin histopathology was necrose of epidermis. Gill histopathology were epithelium erosion, hiperplasia of primary lamella, and hiperplasia of secondary lamella.
\end{abstract}

Key words : Comet fish, Gill, Histopathology, Skin.

\begin{abstract}
ABSTRAK
Penelitian ini bertujuan untuk mengetahui pengaruh suhu pemeliharaan berbeda terhadap histopatologi insang dan kulit ikan Komet (Carassius auratus). Penelitian ini menggunakan 30 sampel ikan Komet yang dibagi menjadi tiga perlakuan suhu pemeliharaan, yaitu $25,0{ }^{\circ} \mathrm{C}, 28,5^{\circ} \mathrm{C}$, dan $32,0^{\circ} \mathrm{C}$. Hasil penelitian memperlihatkan kerusakan jaringan pada kulit dan insang ikan komet pada perlakuan $32^{\circ} \mathrm{C}$. Kerusakan pada jaringan kulit berupa nekrosis epidermis. Kerusakan jaringan insang berupa terlepasnya epitelium, hiperplasia lamella primer, dan hiperplasia lamella sekunder.
\end{abstract}

Kata Kunci : Histopatologi, Ikan Komet, Insang, Kulit.

Asep Sumantri, Mulyana dan Fia Sri Mumpuni. 2017. Pengaruh Perbedaan Suhu Pemeliharaan terhadap Histopatologi Insang dan Kulit Ikan Komet (Carassius auratus). Jurnal Mina Sains 3(1): $1-7$.

\section{PENDAHULUAN}

\section{Latar Belakang}

Indonesia yang beriklim tropis mempunyai potensi ikan hias mencapai 300 juta ekor/tahun yang terdiri dari 240 jenis ikan hias laut dan 226 jenis ikan hias air tawar (Lingga dan Susanto 2003). Beberapa jenis ikan hias air tawar telah sukses dikultur, salah satunya ialah ikan Komet. Ikan Komet merupakan salah satu strain dari ikan mas koki yang kebanyakan merupakan hasil kawin silang antara beberapa jenis ikan karper. Ikan
Komet mempunyai imunitas tubuh yang lebih baik daripada ikan mas Koki (Ardi 2008).

Faktor lingkungan dapat menjadi salah satu faktor yang menyebabkan ikan menjadi stres. Faktor lingkungan tersebut bisa berupa faktor fisika, kimia, dan biologis. Stres karena lingkungan yang buruk dapat berdampak pada keadaan jaringan dan menimbulkan efek patologis pada organ ikan. Stres dapat berdampak pada keadaan jaringan dan menimbulkan efek patologis misalnya pada hati, limpa, dan insang. Hal ini disebabkan 
oleh rendahnya kandungan oksigen terlarut dalam air (Harper dan Jeffrey 2008).

Suhu merupakan faktor yang sangat penting di dalam air karena bersama-sama dengan zat yang ada didalamnya akan menentukan densitas air, kejenuhan air, mempercepat reaksi kimia air, dan mempengaruhi kandungan oksigen terlarut dalam air (Irianto 2005). Perubahan temperatur air sebesar $5^{\circ} \mathrm{C}$ di atas normal bisa menyebabkan ikan stres bahkan kerusakan jaringan (histopatologi) dan kematian (Irianto 2005). Kulit merupakan lapisan terluar yang terdapat di bagian luar tubuh ikan, berfungsi menutupi dan melindungi permukaan tubuh dari gangguan lingkungan, pathogen, limbah atau racun yang ada di dalam perairan. Oleh karena itu perlu dilakukan penelitian terhadap pengaruh gangguan suhu terhadap jaringan insang dan kulit pada ikan Komet.

\section{Tujuan}

Penelitian ini bertujuan untuk mengetahui histopatologi kulit dan insang ikan Komet (Carassius auratus) yang dipelihara pada suhu yang berbeda.

\section{Hipotesis}

Suhu pemeliharan yang berbeda dapat memicu stress dan berpengaruh terhadap perubahan jaringan kulit dan insang ikan Komet (Carassiuss auratus).

\section{BAHAN DAN METODE}

\section{Waktu dan Tempat Penelitian}

Penelitian ini dilaksanakan pada bulan September 2015 hingga bulan April 2016. Penelitian ini menggunakan metode sampling. Proses analisis dan pemeriksaan jaringan insang dan kulit pada sampel ikan dilakukan di Laboratorium Perikanan Universitas Djuanda Bogor.

\section{Bahan dan Alat}

Bahan yang dibutuhkan ialah ikan komet sebagai objek penelitian yang dibeli dari toko ikan hias di Kecamatan Ciampea, Kabupaten Bogor sebanyak 50 ekor, larutan BNF, ethanol $70 \%$, ethanol $80 \%$, ethanol $90 \%$, ethanol $95 \%$ dan ethanol absolut, xylol, paraffin, hematoksilin, eosin, entelan dan botol sampel.

Peralatan yang dipergunakan dalam penelitian percobaan ini ialah alat bedah sampel (gunting dan pisau), pinset, oven, kaca tutup, pemanas air (heater), 3 buah akuarium berukuran $30 \mathrm{~cm}$ x $30 \mathrm{~cm}$ x $30 \mathrm{~cm}$, kaca objek, mikroskop binokuler, dan mikrotom.

\section{Metode Penelitian}

Tiga puluh ekor ikan Komet yang berukuran $4-5 \mathrm{~cm}$ yang berasal dari toko ikan hias yang berada di Kecamatan Ciampea, Kabupaten Bogor, digunakan sebagai sampel dalam penelitian ini. Kemudian dibawa ke Laboratorium Perikanan Universitas Djuanda Bogor untuk diadaptasi selama 3 hari. Pemeliharaan ikan memmpergunakan sistem air tidak mengalir dan suhu air relatif stabil. Percobaan ini terdiri atas 3 perlakuan. Perlakuan I adalah dengan suhu air $25^{\circ} \mathrm{C}$, perlakuan II $28,5^{\circ} \mathrm{C}$, dan perlakuan III $32^{\circ} \mathrm{C}$ dan pada setiap perlakuan, jumlah ikan yang berada dalam akuarium perlakuan bsebanyak 10 ekor. Perlakuan dilakukan selama 6 jam mulai dari Jam 07.00 -13.00 WIB, selama perlakuan dalam kurun waktu 6 jam pada jam 07.15, 07.45, 08.00, 10.00, 13.00 ikan diambil contohnya sebanyak 2 ekor dari setiap perlakuan untuk dijadikan preparat jaringan insang dan kulit. Pemeriksaan histologi dilakukan menurut prosedur sebagai berikut.:

(1) Fiksasi jaringan otot dan kulit dalam larutan BNF selama 24 jam

(2) Dehidrasi dengan ethanol $70 \%$ selama 1-2 hari, ethanol $80 \%$ selama 2 jam, ethanol $90 \%$ selama 2 jam, ethanol $95 \%$ selama 2 jam, ethanol $95 \%$ selama 2 jam, dan ethanol absolut selama 12 jam

(3) Clearing menggunakan ethanol absolute:xylol dengan perbandingan 1:1 selama 0,5 jam, xylol I selama 0,5 jam, xylol II selama 0,5 jam, xylol III selama 0,5 jam, dan xylol:paraffin dengan perbandingan 1:1 yang dilakukan di dalam oven pada suhu $58^{\circ} \mathrm{C}$ selama 0,75 jam

(4) Embedding menggunakan paraffin I dalam oven pada suhu $58^{\circ} \mathrm{C}$ selama 0,75 jam, paraffin II dalam oven pada suhu $58^{\circ} \mathrm{C}$ selama 0,75 jam, paraffin III dalam oven pada suhu $58^{\circ} \mathrm{C}$ selama 0,75 jam, kemudian dicetak dalam paraffin

(5) Sayatlah jaringan dalam blok paraffin dengan ketebalan 5 mikron

(6) Deparaffinasi dengan xylol I selama 3 menit dan xylol II selama 3 menit 
(7) Rehidrasi dengan ethanol absolut I selama 3 menit, ethanol absolut II selama 3 menit, ethanol 95\% selama 3 menit, ethanol 90\% selama 3 menit, ethanol $80 \%$ selama 3 menit, ethanol $70 \%$ selama 3 menit, ethanol 50\% selama 3 menit, kemudian dicuci dengan akuades

(8) Warnai dengan hematoksilin selama 7 menit, pencucian dengan air selama 3 detik, eosin selama 3 detik, dan pencucian dengan air selama 3 detik

(9) Dehidrasi dengan ethanol 50\% selama 2 menit, ethanol $70 \%$ selama 2 menit, ethanol $85 \%$ selama 2 menit, ethanol $90 \%$ selama 2 menit, ethanol absolut I selama 2 menit, ethanol absolut II selama 2 menit, xylol I selama 2 menit, dan xylol II selama 2 menit

(10) Mounting menggunakan zat perekat enthelan, ini dibiarkan selama semalam agar kering dan tidak ada udara antara kaca tutup dan kaca obyek. Jaringan otot dan kulit ikan Komet yang sudah diwarnai ini akan diamati di bawah mikroskop binokuler dengan perbesaran 100 kali, kemudian dibuat foto jaringannya.

\section{Parameter yang Diamati}

Parameter yang diamati pada penelitian ini yaitu kerusakan pada jaringan insang dan kulit ikan Komet pada pemeliharaan suhu yang berbeda.

\section{Analisis Data}

Data yang diperoleh kemudian dianalisa secara deskriptif berdasarkan hasil histopatologi insang dan kulit ikan Komet dari tiap-tiap sampel yang diamati.

\section{HASIL DAN PEMBAHASAN}

\section{Hasil}

Berdasarkan hasil pemeriksaan selama proses penelitian, didapat kerusakan pada jaringan kulit dan insang ikan Komet yang diberi perlakuan suhu pemeliharan berbeda dalam kurun waktu 6 jam. Hasil pemeriksaan didapat kerusakan pada jaringan kulit ikan Komet pada perlakuan $\mathrm{C}\left(32^{\circ} \mathrm{C}\right)$ yaitu terjadi kerusakan pada jaringan epidermis dan hasil dari pengamatan sampel jaringan insang ikan Komet yang diberi perlakuan suhu pemeliharan berbeda, terdapat kerusakan pada sampel pelakuan $\mathrm{C}\left(32^{\circ} \mathrm{C}\right)$, insang mengalami hiperplasia lamella sekunder dan hiperplasia lamella primer serta epitelium pada lamella terlepas. Sedangkan pada perlakuan A $\left(25^{\circ} \mathrm{C}\right)$ dan $\mathrm{B}\left(28,5^{\circ} \mathrm{C}\right)$ tidak terjadi perubahanan maupun kerusakan struktur jaringan kulit dan insang ikan Komet (Carassius auratus). Kerusakan jaringan pada kulit dan insang ikan Komet disajikan pada Tabel 1, Gambar 1, Gambar 2, dan Gambar 3.

Tabel 1 Hasil Pemeriksaan Histopatologi Kulit dan Insang Ikan Komet

\begin{tabular}{cccc}
\hline & \multicolumn{3}{c}{ Perlakuan } \\
Perubahan Histopatologi & A & B & C \\
\cline { 2 - 4 } Kulit dan insang ikan Komet & - & - & + \\
Kerusakan epidermis & - & - & + \\
Epithelium lepas & - & - & + \\
Hiperplasia lamella primer & - & - \\
Hiperplasia lamella sekunder & $-(-)$ Tidak terjadi kerusakan pada jaringan kulit atau insang \\
Keterangan: Terjadi kerusakan pada jaringan kulit dan insang
\end{tabular}




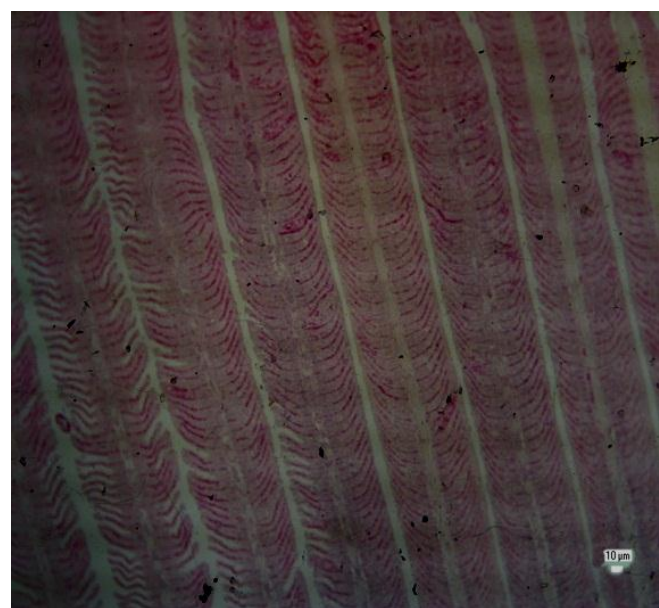

(A. Insang)

Gambar 1 Histopatologi (A) insang dan (B) kulit Ikan Komet (Perlakuan A. $25^{\circ} \mathrm{C}$ )

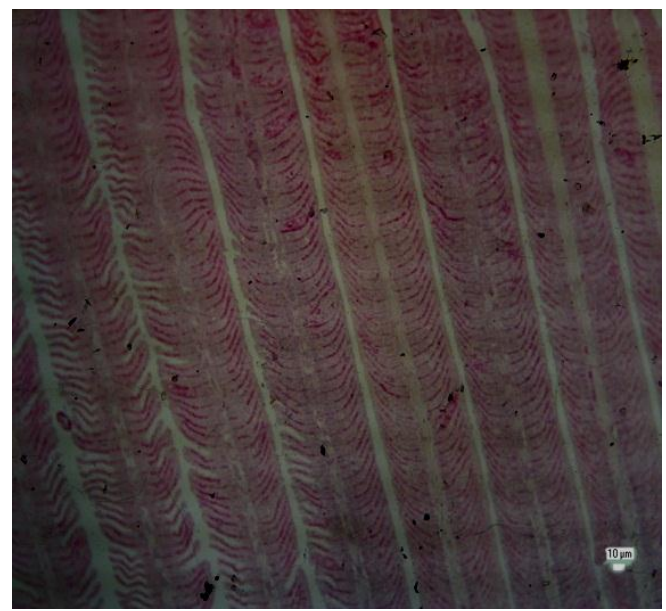

(A. Insang)

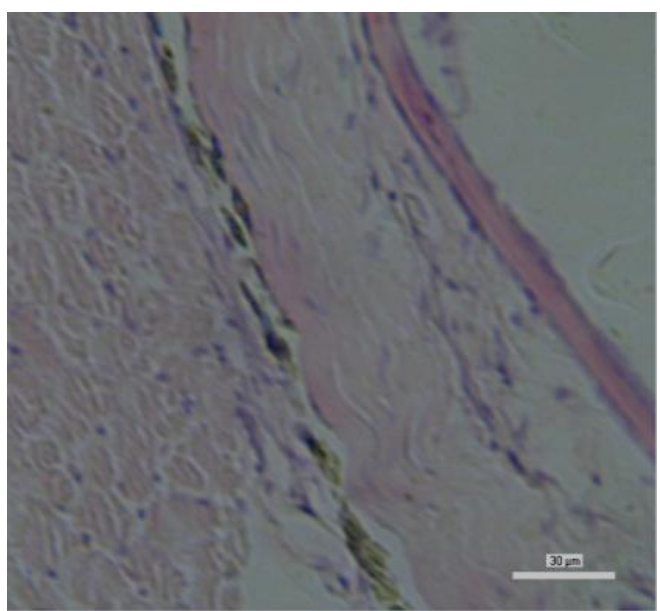

(B. Kulit)

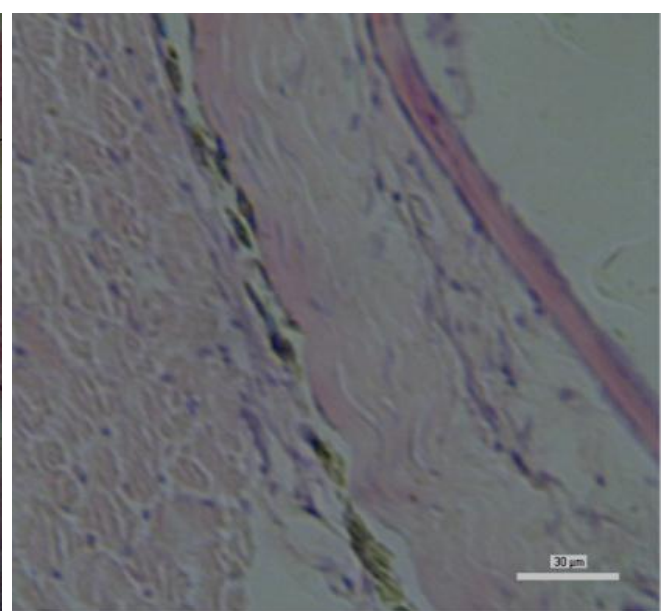

(B. Kulit)

Gambar 2 Histopatologi (A) insang dan (B) kulit Ikan Komet (Perlakuan 28,5 $5^{\circ}$ )

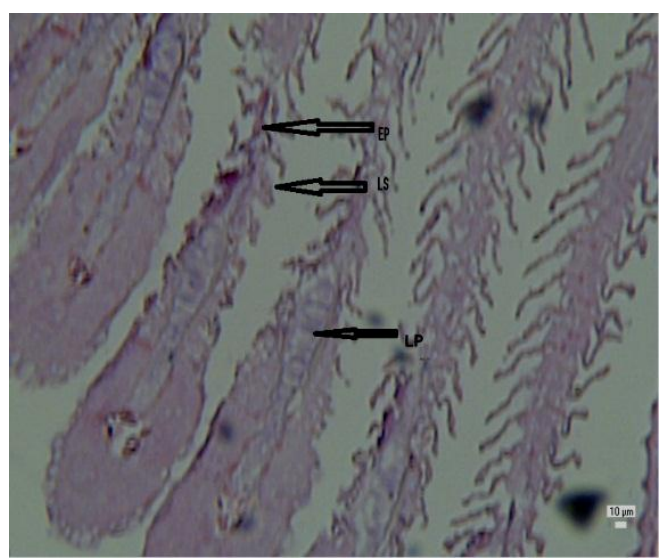

(A. Insang)

EL :Epithelium lepas

LP : Hiperplasia Lamela sekunder

LS: Hiperplasia Lamela primer 
Kualitas air selama perlakuan dengan suhu pemeliharaan yang berbeda dalam kurun waktu 6 jam (Tabel 2) dan tidak mengalami fluktuasi suhu. Faktor-faktor yang dapat mempengaruhi kehidupan ikan pada penelitian ini selain suhu, seperti DO dan $\mathrm{pH}$ dikatakan layak dan tidak berpengaruh pada tingkat stres ikan dan perubahan stuktur jaringan dan insang ikan Komet.

Tabel 2 Kualitas Air Selama Penelitian

\begin{tabular}{ccccc} 
Parameter & \multicolumn{3}{c}{ Perlakuan } & $\begin{array}{c}\text { Kisaran optimal } \\
\text { (Wicaksono 2005) }\end{array}$ \\
\cline { 2 - 4 } & $\mathrm{A}$ & $\mathrm{B}$ & $\mathrm{C}$ & \\
\hline Suhu $\left({ }^{\circ} \mathrm{C}\right)$ & $25^{0} \mathrm{C}$ & $28,5^{0} \mathrm{C}$ & $32^{0} \mathrm{C}$ & \\
DO $(\mathrm{ppm})$ & $4,3-4,4$ & $48,5^{0} \mathrm{C}$ & $32^{0} \mathrm{C}$ & $18-28$ \\
$\mathrm{pH}$ & $6,8-69$, & $6,8-6,4,4,1$ & 3,0 \\
\hline
\end{tabular}

\section{Pembahasan}

\section{Kerusakan Struktur Jaringan pada Kulit}

Berdasarkan hasil pengamatan yang dilakukan dengan menggunakan sampel uji ikan Komet sebanyak tiga puluh ekor yang diperoleh dari kios ikan di Kecamatan Ciampea Kabupaten Bogor, didapat kerusakan struktur jaringan kulit ikan Komet yang disebabkan oleh pengaruh suhu yang berbeda selama 6 jam pemeliharaan. Sampel uji yang mengalami kerusakan oleh pengaruh suhu terjadi pada $\mathrm{C}\left(32^{\circ} \mathrm{C}\right)$.

Kulit merupakan bagian organ terluar pada ikan serta kulit juga merupakan organ yang paling luas, permukaan yang membungkus seluruh bagian luar tubuh ikan sehingga kulit juga berperan sebagai pelindung tubuh terhadap ganguan lingkungan bila ikan terpapar lingkungan yang kurang menguntungkan, kemungkinan pada jaringan kulit akan terjadi pengelupasan epidermis, jaringan kulit epidermis berada paling luar pada struktur jaringan kulit, serta paling rentan mengalami kerusakan karena jaringan kulit epidermis sangat tipis dan memungkinkan terjadi kerusakan apabila terjadi serangan pada ikan yang disebabkan oleh gangguan lingkungan atau perubahan suhu. Jika lingkungan perairan terganggu ikan akan mempertahankan diri dengan mengeluarkan mukus (lendir) sebagai pertahanan pertama saat lingkungan mengalami gangguan seperti perubahan suhu. Kerusakan pada jaringan kulit epidermis disebabkan ikan mengalami iritasi dikarenakan perubahan suhu yang tinggi sehingga ikan mensekresi mukus berlebih.

Kejadian ini sama dengan hasil penelitian yang dilakukan oleh Sari (2013) menyatakan bahwa ektoparasit Argulus japonicus memasukkan stylet ke dalam epidermis sampai lapisan jaringan dibawahnya hal ini berpotensi mengakibatkan kerusakan jaringan epidermis karena penetrasi stylet menembus lapisan epidermis dengan cara menusuk sehingga mengakibatkan pengikisan epitel epidermis. Saber (2011) menambahkan bahwa kerusakan kulit dan jaringan yang terjadi berkaitan dengan perubahan lingkungan atau perubahan temperatur yang tinggi dikarenakan ikan yang mensekresi mukus dan tidak bisa mempertahankan diri dari perubahan lingkungan, sehingga sangat rentan mengalami kerusakan pada jaringan kulit epidermis. Kerusakan struktur jaringan kulit epidermis disebabkan ikan akan mensekresikan mukus sebagai upaya untuk mempertahankan diri dari lingkungan, semakin jauh perbedaan antara suhu tubuh dan lingkungan maka ikan akan melakukan upaya adaptasi untuk mempertahankan diri dari lingkungan (osmoregulasi) (Fujaya 2008). Mukus merupakan glikoprotein yang bersifat basa atau netral yang berfungsi sebagai perlindungan atau proteksi, menurunkan terjadinya friksi atau gesekan, antipatogen, membantu pertukaran ion, membantu pertukaran gas dan air (Shephard 1994). 


\section{Kerusakan Struktur Jaringan Pada Insang}

Hasil penelitian ini menunjukan bahwa perbedaan suhu pemeliharaan yang berbeda dapat berpengaruh terhadap histopatologi insang ikan Komet dan menyebabkan lepasnya epithelium, hiperplasia lamella primer dan hiperplasia lamella sekunder sampel histopatologi insang yang mengalami perubahan atau kerusakan terjadi pada sampel perlakuan C $\left(32^{0} \mathrm{C}\right)$. Suhu merupakan salah satu indikator yang penting dalam perairan, perubahan suhu atau perbedaan suhu dengan habitat asli ikan dapat memberi pengaruh terhadap jaringan insang dikarenakan insang merupakan salah satu organ yang sangat sensitif jika terjadi perubahan ataupun gangguan pada lingkungan perairan. Terlepasnya sel epitel pada lamela primer dan lamela sekunder yang terjadi dikarenakan insang mengeluarkan mukus sebagai bentuk pertahanan diri insang terhadap perubahan lingkungan. Lapisan epitel insang yang tipis dan berhubungan langsung dengan lingkungan luar menyebabkan berpeluang besar mengalami perubahan atau kerusakan. Epithelium lepas disebabkan oleh pelepasan sel-sel dari jaringan penyokongnya (membran basal) dikarenakan perubahan suhu yang tinggi sehingga mempengaruhi sistem kerja insang.

Sel-sel lamella sangat berperan penting dalam proses respirasi terutama untuk difusi $\mathrm{O}_{2}$ dari dalam air, ketika keadaan fisika (suhu) perairan tidak dalam kondisi baik maka sel-sel lamella juga akan terganggu. Hiperplasia pada insang ikan disebabkan oleh pengaruh suhu yang berbeda dengan habitatnya dan menyebabkan berubahnya struktur sel klorida, serta diikuti oleh lepasnya epitel dari lamela sekunder yang dapat menyebabkan terganggunya fungsi epitel sebagai penangkap gas terlarut. Perubahan suhu mengakibatkan insang mengalami iritasi dan mengeluarkan lendir sebagai perlindung terhadap perubahan lingkungan. Hiperplasia lamella primer dan hiperplasia lamella sekunder dapat terjadi pada insang ikan diawali dengan beberapa kejadian diantaranya edema, kematian sel dan lepasnya sel-sel epithelium pada lamella insang. Kejadian ini sesuai dengan penelitian yang telah dilakukan oleh Sipahutar et al. (2013) yang menyatakan pada suhu $30{ }^{0} \mathrm{C}-32{ }^{0} \mathrm{C}$, terlepasnya epithelium pada lamella, hiperplasia lamella sekunder dan hiperplasia lamella primer pada insang ikan Nila (Oreochromis nilocticus). Saber (2011) menambahkan bahwa lendir berfungsi untuk melindungi lamella insang dari gangguan lingkungan, gangguan pada lingkungan atau perubahan suhu dapat mengakibatkan perubahan struktur jaringan insang, seperti hiperplasia lamella primer, hiperplasia lamella sekunder edema dan lepasnya lapisan epithelium. Suhu air yang tinggi dan rendah menyebabkan ikan akan bekerja lebih maksimal untuk memompakan air lebih cepat ke dalam permukaan insang untuk proses pernapasan (Reebs 2009). Kerusakan kecil bisa menyebabkan terganggunya fungsi insang sebagai pengatur tekanan osmosis dan ikan akan sulit bernafas. Perubahan temperatur sebesar $5^{\circ} \mathrm{C}$ di atas normal bisat menyebabkan ikan menjadi stress, bahkan menimbulkan kerusakan pada jaringan dan kematian pada ikan (Kordi 2000).

\section{Kualitas Air}

Kualitas air selama proses penelitian selain suhu sebagai perlakuan relatif berada pada kisaran normal yaitu DO pada perlakuan A yaitu 4,3 - 4,4, perlakuan B berkisar 4,1 4,2 sedangkan pada perlakuan $\mathrm{C} 4,0-4,1$ dan pH pada perlakuan A dan B berkisar $6,8-6,9$ sedangkan pada perlakuan $\mathrm{C}$ pH $6,7-6,8$. Kelangsungan hidup ikan dapat dipengaruhi oleh dua faktor, faktor internal meliputi genetik dan kondisi fisiologis ikan serta faktor eksternal yang berhubungan denganlingkungan (suhu). Suhu merupakan salah satu faktor fisika yang sangat penting di dalam air karena bersama-sama dengan zat/unsur yang terkandung didalamnya akan menentukan massa jenis air, densitas air dan kejenuhan air. Hasil dari penelitian bahwa perubahan suhu yang tinggi dapat memberi pengaruh terhadap kehidupan ikan, serta dapat merusak struktur jaringan dan fungsi insang serta kulit sebagai organ yang sensitif terhadap perubahan lingkungan.

\section{KESIMPULAN DAN SARAN}

\section{Kesimpulan}

Pengaruh perbedaan suhu pemeliharaan ini berpengaruh terhadap histopatologi kulit dan insang ikan Komet (Carassius auratus). 
Perubahan pada struktur kulit pada perlakuan $\mathrm{C}\left(32^{\circ} \mathrm{C}\right)$ yaitu rusaknya jaringan epidermis dan pada struktur jaringan insang pada perlakuan C $\left(32^{0}\right.$ C) epithelium lepas, hiperplasia lamela primer dan hiperplasia lamela sekunder.

\section{Saran}

Perlu dilakukan penelitian lanjutan pengaruh suhu terhadap histopatologi insang dan kulit ikan Komet, dengan perlakuan suhu yang lebih tinggi untuk mengetahui tingkat lanjutan kerusakan pada jaringan kulit dan insang ikan Komet (Carassius auratus).

\section{DAFTAR PUSTAKA}

Ardi. 2008. Pembenihan Ikan Mas Komet (Carassiu s auratus auratus). On line at http://www.docstoc.com/ docs/ 13480410/ PEMBENIHAN - IKAN-MAS KOMET Carassius-auratus [diakses tanggal 06 September 2015].

Fujaya Y. 2008. Fisiologi Ikan Dasar Pengembangan Teknik Perikanan. Jakarta: Rineka Cipta.

Irianto A. 2005. Patologi Ikan Teleostei. Yogyakarta: Gadjah Mada University Press.
Lingga P, Susanto H. 2003. Ikan Hias Air Tawar. Jakarta: Penebar Swadaya.

Reebs SG.2009. Oxygen and Fish Behavior. www.howfish behave.ca/pdf/oxygen. pdf. pada 27 Agustus 2015.

Roberts RJ. 2001. Fish Pathology. 3rd ed. WB Saunders. Toronto.

Sari RER. 2010. Perubahan Histopalogi Jaringan Kulit Ikan Komet (Carassius auratus auratus) Akibat Inasfestasi Argulus japonicus. [Skripsi] Surabaya: FPIK Universitas Airlangga.

Saber TH. 2011. Histological Adaptation to Thermal Changes in Gills of Common Carp Fishes Cyprinus carpio L. Jou.Raf. Sci., Vol. 22, No.1 pp 46 - 55.

Shephard KL.1994. Functions for fish mucus. Rev.Fish Biology. Fish 4:401.

Sipahutar LW, Aliza D, Winaruddin, Nazaruddin. 2013. Gambaran Histopathologi Insang Ikan Nila (Oreochromis niloticus) Yang Dipelihara Dalam Temperatur Air Di Atas Normal. Banda Aceh: FKH Universitas Syiah Kuala. 